\title{
Geochemical characterization of components of the groundwater flow system in the basin of Mexico
}

\author{
Selene Olea-Olea ${ }^{1, *}$, Oscar Escolero ${ }^{2}$, Jürgen Mahlknecht ${ }^{3}$ \\ ${ }^{1}$ Posgrado en Ciencias de la tierra, Universidad Nacional Autónoma de México, Ciudad Universitaria, \\ 04510, Ciudad de México, Mexico \\ ${ }^{2}$ Departamento de Dinámica Terrestre y Superficial, Universidad Nacional Autónoma de México, \\ Ciudad Universitaria, 04510, Ciudad de México, Mexico \\ ${ }^{3}$ Centro del Agua para América Latina y el Caribe. Tecnológico de Monterrey, Campus Monterrey, \\ 64849, Nuevo León, Mexico
}

\begin{abstract}
More than 21 million people live within the Basin of Mexico. Water is the main concern of this large population, where groundwater has been intensively exploited, leading to subsidence and fracturing of the ground. It is for this reason that it's very important to understand the behavior of groundwater flow system components. This knowledge can help to more effectively manage water use and conserve the recharge zones. The main purpose of this study is to identify and characterize the components of groundwater flow system. Cluster analysis was used to classify 303 groundwater samples into groups. The groups show that chemical concentrations increase along the trajectories of groundwater flow. We describe these groups and identify three components in the flow system; the upper zone, the intermediate zone and the inferior zone. Different water management policies are suggested for each system component, because they have different response times to the actions taken in their use and conservation.
\end{abstract}

\section{Introduction}

The Basin of Mexico is a closed catchment located in the Mexico Trans-volcanic Belt [1]. The basin has a drainage area of about $9600 \mathrm{~km}^{2}$. The abrupt relief of the surrounding mountains, with altitudes of more than $5000 \mathrm{~m}$ a. s. 1, inclines towards the flat-lying center of the basin to an altitude of approximately $2230 \mathrm{~m}$ a. s. 1 [2]. Thermal mineral springs occur along lineaments thought to be fractures in the rocks below the alluvial fill [3].

People have occupied this basin for some 15,000 years and Mexico City has developed within the basin, so that today a population of more than 21 million inhabitants reside within the basin [4]. Additionally, several million people live in other communities nearby. Groundwater extraction in the last 60 years has caused a decline in the groundwater level and land subsidence. In recent years, water quality, rather than quantity, has become a

\footnotetext{
* Corresponding author: selene.olea.olea@gmail.com
} 
concern in some areas of the country. Mexico City depends heavily on shared groundwater: more than $72 \%$ of the water supply is pumped from groundwater systems by neighboring states [5]. Lack of knowledge of the functioning of the flow system is one of the reasons for the intensive exploitation of the groundwater in the basin. Therefore, it is very important to understand groundwater behavior in the basin in order to design better strategies for water exploitation, water management and water conservation. We therefore study and evaluate the components of this system using the cluster analysis, a very powerful classification tool.

\section{Methodology}

This study used unpublished data from the National Water Commission of Mexico for the year 2017 to create the water table map of the basin. A total of 303 groundwater samples were collected during June to October 2018 from 43 springs and 260 wells, with in-situ measurement of the following field parameters: electrical conductivity (EC), temperature, $\mathrm{pH}$ and hardness. The samples were collected in polyethylene bottles and filtered in situ through $0.45 \mu \mathrm{m}$ Millipore cellulose nitrate filter. Cations and trace elements samples were also acidified with $\mathrm{HNO} 3$ to $\mathrm{pH} \sim 2$ [6]. All samples were stored at approximately $4{ }^{\circ} \mathrm{C}$ before analysis. Major chemical constituents were analyzed by liquid chromatography and trace elements by inductively coupled plasma optical emission spectrometry (ICP-OES).

Fifteen physico-chemical constituents, the cations $\mathrm{Na}^{+}, \mathrm{K}^{+} \mathrm{Ca}^{2+}$, and $\mathrm{Mg}^{2+}$, anions $\mathrm{HCO}^{3-}, \mathrm{Cl}^{-}$, and $\mathrm{SO}_{4}{ }^{2-}$, trace elements $\mathrm{Si}, \mathrm{Sr}$, and $\mathrm{Zn}$ and $\mathrm{pH}, \mathrm{t}, \mathrm{EC}$ and hardness were used for the multivariate statistical analysis. Agglomerative hierarchical cluster analysis was done by means of Ward's method [7] using squared Euclidean distances as a measure of similarity. Ward's method enables an analysis of variance approach to evaluate the distances between the clusters in order to minimize the sum of squares of any two clusters [8]. The cluster package in RStudio was used for the multivariate statistical analysis.

\section{Results and discussion}

The entire basin is considered as a single unit where groundwater moves. Groundwater flows within the basin are in contact with basic volcanic rocks (basalt, andesite, tuffs, ash deposits), conglomerates with volcanic clasts, sands and gravels of volcanic and sedimentary origin. Wells have depth from 100 to $450 \mathrm{~m}, 3$ wells reach depth greater than $900 \mathrm{~m}$, and the deepest well extends to $2020 \mathrm{~m}$.

Water map (Fig. 1) shows groundwater flow direction in the basin. Water moves mainly from the southeast and northeast towards the middle of the basin.

Based on the standardized physico-chemical data, cluster analysis was performed to classify water sampling points. Figure 2 shows cluster dendrogram classification of the basin. Groundwater is classified into four groups $(1,2,3,4)$ (Fig. 1). These groups show different characteristics. Chebotarev [9] concluded that groundwater tends to evolve chemically with time towards the composition of seawater, i.e. from $\mathrm{HCO}^{3-} \rightarrow \mathrm{HCO}^{3-}+$ $\mathrm{SO}_{4}{ }^{2-} \rightarrow \mathrm{SO}_{4}{ }^{2-}+\mathrm{HCO}^{3-} \rightarrow \mathrm{SO}_{4}{ }^{2-}+\mathrm{Cl}^{-} \rightarrow \mathrm{Cl}^{-}+\mathrm{SO}_{4}{ }^{2-} \rightarrow \mathrm{Cl}^{-}$. The groups respond to this chemical evolution, group 1 being least evolved and group 4 most evolved. This evolution is controlled by water-rock interaction and residence times. We also use cluster classification and water table map to define recharge zones in the basin. For example; Group 1 waters lie in the southwest boundary region of the basin and are related to a less evolved chemical composition. Group 1 can be considered a recharge zone.

Group 2 waters are observed after Group 1 in the flow direction, which according to the Chebotarev evolution could be related to the increase of mineral composition as a consequence of longer subsurface residence time. 
Groups 3 and 4 are progressively located along the direction of flow. They are divided into two zones. The first flows from the southwest area into the central part of basin and the second from northeast area to the central part of basin. In the first zone, the four water groups follow the groundwater flow direction, with Group 1 to 4 progressively evolving from less evolved waters to waters with higher dissolved contents along groundwater flow paths. The water evolves from its recharge zone as it interacts with the rocks until reaching the last stage of the Chebotarev sequence.

Within the second zone are mainly groups 3 and 4 . Group 2 is present in a small proportion and group 1 is present only on 1 site in middle part of basin. The waters of group 3 and 4 must have evolved since recharge in the subsoil. One cause could be that water recharges in the NE zone and continues to evolve in the direction of flow to its location in the NW. Another possibility could be that water recharges in the NW and continues to evolve in the direction of flow to its $\mathrm{N}$ location. We do not consider inter-basin flow because there is no other basin topographically higher than the Basin of Mexico.

Temperature and EC are two variables very related in the study of groundwater flow systems (Fig. 3). Group 1 has low temperature and low EC, this may be due waters of recent infiltration (had little time to interact with rocks for mineral dissolution). Temperature responds to recharge temperature of the area, with colder waters that are characteristics of mountain climate. Groups 2, 3 and 4 have water temperature that increase with EC. Groups 3 and 4 have the highest temperature and highest EC. The elevated EC values reflect increasing mineral dissolution along groundwater flow paths. The Chebotarev chemical evolution could explain the increase in EC. Temperature increase could be related to input of geothermal waters into the deeper portions of the basin [10]. The Mixhuca fault [11] and Santa Catarina graben [12] (Fig. 1) favor the circulation of fluids that come from greater depths. For example; there is a thermal spring near Santa Catarina graben.

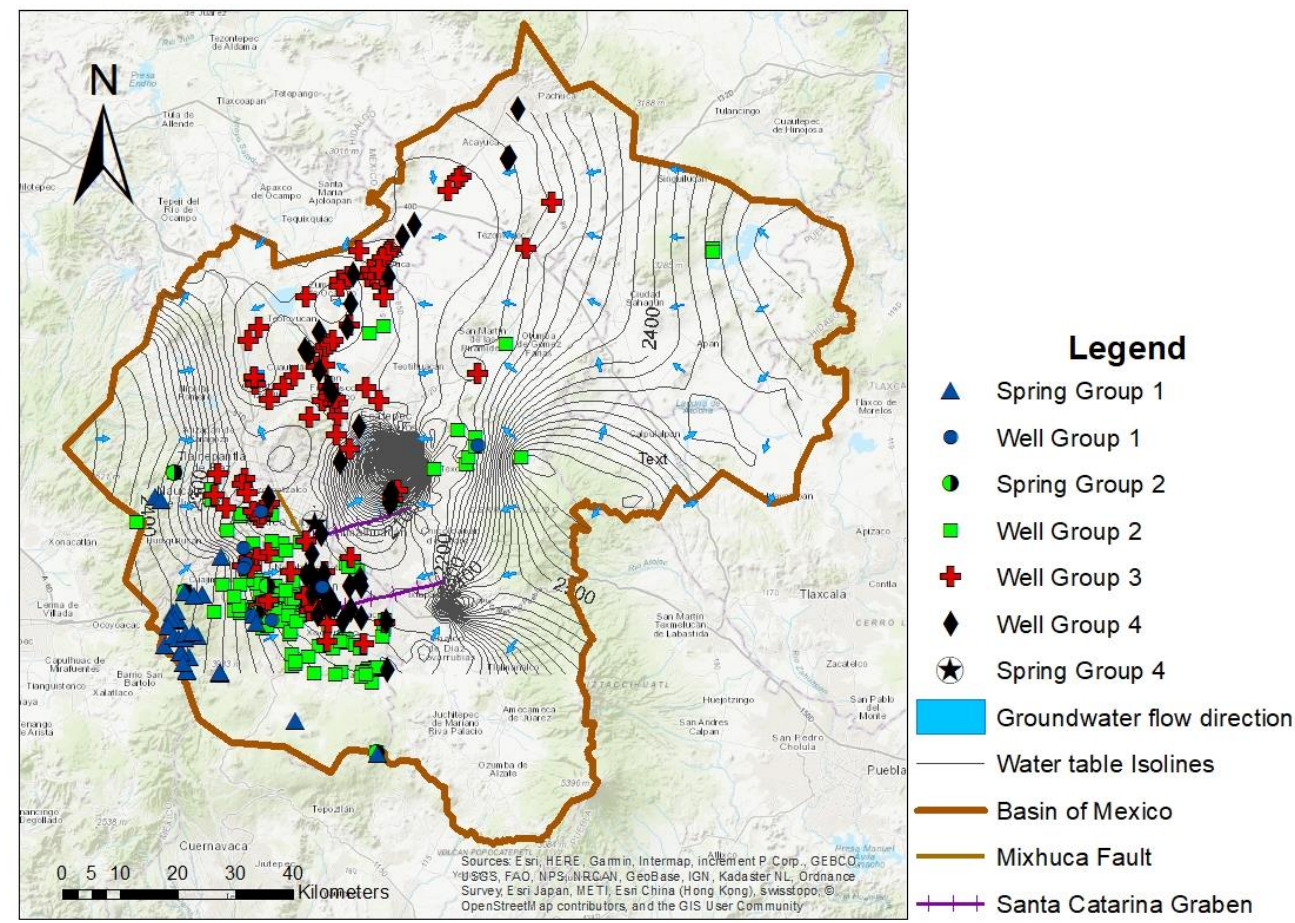

Fig. 1. Water table and sample location map showing geological structures $[10,11]$. 


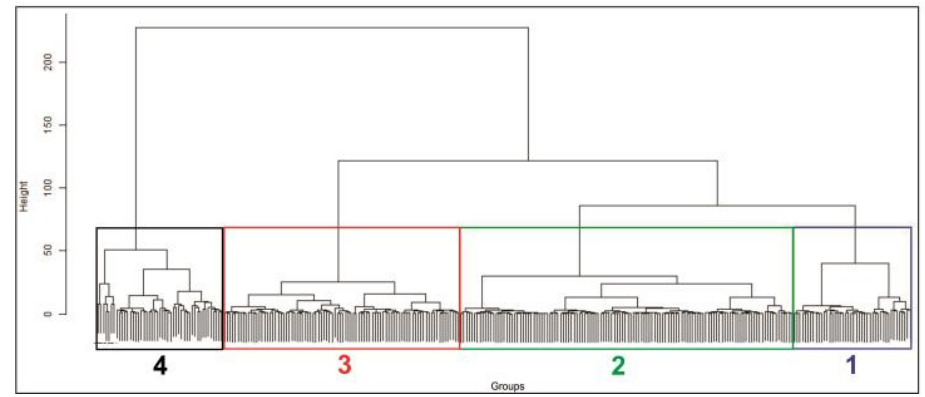

Fig. 2. Classification dendrogram for 303 groundwaters of the Basin of Mexico.

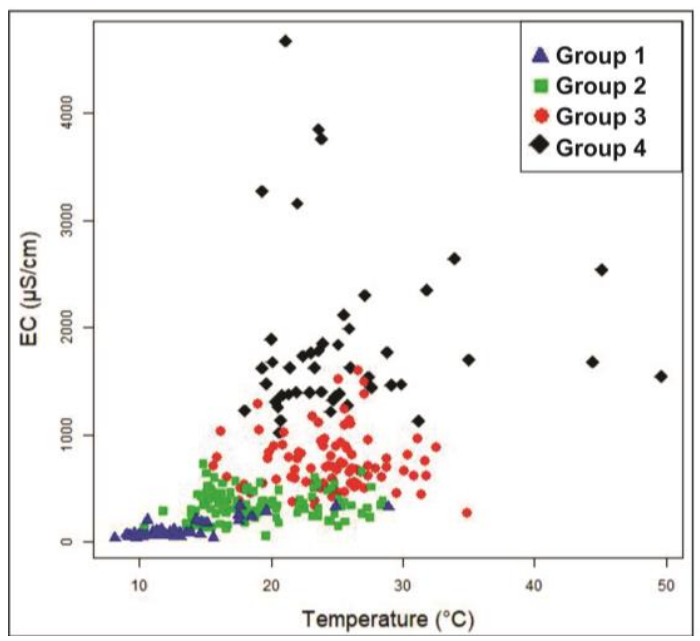

Fig. 3. Scatter plot of electrical conductivity (EC) versus temperature (T).

Makarenko [13] proposes to divide the components of the flow system into 3 zones; the upper zone, the intermediate zone and the lower zone. This classification is related to climatic conditions, travel speed and discharge zone. We relate; Makarenko (a); cluster analysis (b); water table map (c); scatter plot (d) and the Chebotarev chemical evolution (e). We propose that flow system components for the Basin of Mexico are:

1. Group 1 as the upper zone: active flow (a); least chemically evolved (b, c and e); strongly influenced by climatic conditions (a); cold water temperatures (d); recharge zone (c).

2. Group 2 as an intermediate zone: delayed flow (a); medium chemical evolution (b, c and e); little climatic influence (a).

3. Group 3 and 4 as lower zones: very slow flow (a); greater chemical evolution (b, c and e); no influence of the current climate (a); hot water temperatures (d); influenced by geothermal gradient (d).

\section{Summary and Conclusions}

Identifying the components of the flow system of the Basin of Mexico is essential to understand its functioning. The use of techniques such as cluster analysis, scatter diagrams and chemical evolution of Chebotarev gave us 3 components; superior, intermediate and inferior. The upper zone is related with recent infiltration. This zone is located in the southeast boundary area of the basin. The intermediate zone reflects the water's geochemical progressive evolution. Groundwater evolves along the flow path from SW and 
NE towards the middle of the basin. Water-rock interactions are the main process of chemical evolution. The inferior zone is related with high chemical evolution. Higher temperatures are related with geothermal gradient in the inferior zone. Groundwater evolves with residence time along the flow path.

Differences found in components of the flow system can be used to carry out water management strategies. The upper zone that has strongly been influenced by the climate must be managed by a policy that considers climate fluctuations in its extraction and conservation. This zone has active flow, so any change or action that is made on it can be reflected in a short time. However, the lower zone with no influence of the current climate and with very slow flow will not be affected in the short term by the actions taken for its management and conservation.

This research, Project Number IN106718, was supported by "Programa de apoyo a proyectos de investigación e inovación tecnologica" (PAPIIT) (Program of support for projects of research and technological innovation) by UNAM (Nacional Autonomous University of Mexico). We thank Olivia Zamora Martinez from the Chromatography Laboratory and Javier Tadeo León from the Atomic Spectroscopy Laboratory (Institute of Geology, UNAM) for their support in the analyses.

\section{References}

1. E. Vazque-Sánchez, R. Jaimes-Palomera, Geofis Int, 28, 133-190 (1989)

2. W. M. Edmunds, J.J. Carrillo-Rivera, J Hydrol, 258, 1-24 (2002)

3. J. Durazo, R.N. Farvolden, J. Hydrol, 112, 171-190 (1989)

4. United Nations, Revision of World Urbanization Prospects, available from https://population.un.org/wup/ (2018)

5. S. Martinez, et al., Sustain Water Resour Mgmt, 1, 111-123 (2015)

6. C.A.J. Appelo, D. Postma, Geochemistry, Groundwater and Pollution. Taylor and Francis Group. Amsterdam (2005)

7. J.H., Ward Jr., J Am Stat Assoc, 58, 236-244 (1963)

8. A. Michalik, Polish J Env Stud, 17 (3), 357-362 (2008)

9. I.I. Chebotarev, Geochim. Cosmochim. Acta, 8, 22-32 (1955)

10. M. Albu, et al., Mineral and Thermal Groundwater Resources. Chapman \& Hall. Bristol (1997)

11. G.A. Pérez-Cruz, Estudio sismológico de reflexión del subsuelo de la Ciudad de México: México, D.F. Univ Nac Autó México, Tesis de Maestría, 83pp. (1988)

12. J.L. Arce, et al., J Volcanol Geotherm Res, 266, 34-49 (2013)

13. F.A. Makarenko, Acad Sci, 1, 51-71 (1948) 